\title{
Winter Wheat Drought Monitoring and Comprehensive Risk Assessment: Case Study of Xingtai Administrative District in North China
}

\author{
Yanrui Shang ${ }^{1,2}$, Qinghua $\mathrm{Hu}^{1}$, Gongying Liu ${ }^{1}$ and Hanwen Zhang ${ }^{1}$ \\ 1. School of Resources and Environment Science, Hebei Normal University, Shijiazhuang 050024, China \\ 2. Hebei Province Key Laboratory of Environmental Evolution and Ecological Construction, Shijiazhuang 050024, China
}

\begin{abstract}
Drought monitoring is the base for drought coping and adaptation. Xingtai is located in North China's key winter wheat production areas where drought is severe and frequent. The rainfall during winter wheat growing season is just about $1 / 3$ of total demand. Xingtai has typical mountainous, hilly and plain agricultural zones, compound rain-fed and irrigated farming patterns. The winter wheat irrigation has heavily depended on overdraw of groundwater in recent decades. In the study, the MODIS (Moderate-Resolution Imaging Spectroradiometer) images taken at the key winter wheat growing season (Mar. to May) in normal rainfall year (2006) were selected, extracted NDVI (Normalized Difference Vegetation Index) and LST (Land Surface Temperature) data, calculated TVDI (Temperature and Vegetation Drought Index), classified and mapped winter wheat drought intensity. Further, based on TVDI, a CDRA (Comprehensive Drought Risk Assessment) model for winter wheat drought disaster risk assessment was constructed and zoning was made. Verified by winter wheat yield, the risk zoning by CDRA is consistent with actual crop failure space. This method can be used in drought risk management.
\end{abstract}

Key words: Key growing season of winter wheat, TVDI (Temperature and Vegetation Drought Index), CDRA (Comprehensive Drought Risk Assessment), Xingtai of Hebei Province in North China.

\section{Introduction}

Drought is one of the most severe natural hazards that impacts and constraints China's agriculture. In North China, the regional total crop water demand has been exceeding precipitation volume greatly since the end of 1970s and agriculture is highly dependent on irrigation by over development of water resources. As a feedback of ecological and hydrological system, the world's biggest groundwater funnel groups and ground subsidence area has formed in North China. This makes drought situation and water resources scarcity much more severe. The agricultural system's underlying vulnerability to drought is increasing. For example, the extremely intense drought occurred in the spring of 2009 impacted $1,046.7 \times 10^{4} \mathrm{hm}^{2}$ winter wheat area in North China key winter wheat

Corresponding author: Yanrui Shang, professor, main research field: natural disaster and risk management. producing provinces and cities, which accounted for about $43 \%$ of the total winter wheat area. There were 4.29 million people difficult to get drinking water. The State Flood Control and Drought Relief Headquarters of China launched grade III, II and I emergency plan successively. Drought emergency response cost accounted for 0.36 billion US\$ exclusively. Monitoring drought, analyzing the root cause of vulnerability, adjustment of crop structure and production patterns are of urgent need for drought coping and adaptation strategy [1].

Based on MODIS (Moderate-Resolution Imaging Spectroradiometer) images and TVDI (Temperature and Vegetation Drought Index) calculation, a comprehensive risk assessment of winter wheat drought disaster was carried out. It aims at guiding drought response during key winter wheat growing season as well as vulnerability analysis and long-term 
drought adaptation strategy. The paper concludes five parts: the first section is the brief review of drought monitoring methods; the second section is about the background of the studying area; the third section is the calculation of TVDI index, drought intensity classification, mapping and temporal and spatial analyses; the fourth section is comprehensive risk assessment of winter wheat and risk mapping; the fifth section is conclusions and discussions.

\section{Review of Drought Monitor Methods and Drought Index}

Drought index is the standard for characterizing the degree of drought. Choice of a suitable method and index for a certain region and target is of great importance for drought monitoring, forecasting, early warning and making decision of responding and adaptation strategy [2]. According to the monitoring target, the method and index can be classified into two types: one type is based on data gotten from ground station; the other is based on remote sensing images. Drought index based on ground station covers precipitation index, soil moisture index, crop water index and surface water supply index etc.. The Central Meteorological Bureau of China use Precipitation Anomaly Percentage as Meteorological drought index in North China. The Meteorological Department of the United States using PPI (Precipitation Percentage Index) (rainfall/normal rainfall of 100\%) as one of the drought indexes [3] took the standard deviation of precipitation index to determine drought intensity. PDSI (Palmer Drought Severity Index) used precipitation, temperature and available soil water content data to measure soil moisture supply, evaluate the persisting time period of large scale abnormal dry weather and judge the drought evolution trend $[4,5]$. The SPI (Standardized Precipitation Index) based on monthly precipitation and taken into account the impact of precipitation on the groundwater, reservoir water, soil water, snow thickness and runoff, can reflect 1 month, 3 months, 6 months, 12 months and even greater time steps' drought intensity, frequency and time distribution. It has been used by the National Drought Mitigation Center of USA and the WRCC (Western Regional Climate Center) for drought monitor. Shafer, B. A. and Dezman, L. E. [6] concerning of snow cover, runoff, precipitation and water storage, designed SWSI (Surface Water Supply Index) to compare the water supply capacity among different basins. Palmer, W. C. [7] also suggested CMI (Crop Moisture Index), which is based on PDSI. By weekly average temperature and total rainfall as well as last week's CMI, crop drought can be identified. Besides, EDI (Effective Drought Index) [8], ADI (Aggregate Drought Index) [9] and the SPEI (Standardized Precipitation Evapotranspiration Index) [10-12] are all based on the data from ground station. The advantage of them is simple and relatively easy. The drawback is that they could be affected by regional background conditions such as landscape, soil, hydrology and irrigation capacity and so on as well as extreme value and the size of the sample set. There are some other agricultural drought risk indexes based on integrated assessment of a set of natural and social economic characteristics [13, 14]. However, they cannot reflect the real risk situations of growing crops.

Drought index based on remote sensing can reflect the integrated drought conditions through the inversion of surface vegetation growth, soil moisture and surface energy balance. The main methods are thermal inertia, vegetation index and crop water index method. Thermal inertia method is based on the principle that soil moisture is inversely proportional to temperature difference between day and night. Using NOAA-AVHRR (National Oceanic and Atmospheric Administration-Adwanced Very High Resolution Radiometer) satellite image to inverse soil water content, it is suitable for bare or sparsely vegetated area $[15,16]$. Vegetation index includes EVI (Enhanced Vegetation Index) and NDVI (Normalized Difference Vegetation Index) etc. [17]. Among them, 
NDVI is widely used. NDVI may exaggerate the low vegetation cover area's value and compress the high vegetation cover area's index. EVI is more sensitive in the area with high vegetation coverage. Jackson, R. D. et al. [18, 19] established CWSI (Crop Water Stress Index) that can indirectly inverse soil moisture according to the energy balance among soil, vegetation and atmosphere. CWSI has a good relationship with soil moisture below $50 \mathrm{~cm}$. Higher CWSI value means the more serious of crop water shortage. The index evaluates soil moisture by the actual evapotranspiration and potential evapotranspiration ratio. CWSI considers the factors such as vegetation, surface wind speed, water vapor pressure and so on. Some data cannot get from sensing images. So, it is suitable for high vegetation cover in plain area and not suitable for large spatial areas with great microclimate diversity. VSWI (Vegetation Supply Water Index, VSWI $=\mathrm{B} \times$ NDVI $\div$ T) takes NDVI and crop canopy temperature as a factor, and is suitable for the season of high vegetation transpiration. VSWI cannot reflect the difference of surface temperature and NDVI caused by surface environment diversity, so it will be not precise if it is applied in areas with significant regional differentiation.

TVDI reflects crop drought through inversing soil moisture based on the relationship between NDVI and SLT (Surface Land Temperature). For key crop growing stages, TVDI can reflect multiple factors' integrated impact. Qi, S. H. et al. [20] evaluated China's March to May drought in 2000 by TVDI and demonstrated it was feasible. Wang, C. Z. et al. [21] used TVDI inversed soil moisture during April to May (winter wheat) and July to Oct. (summer corn) in Huanghuaihai plain area in North China and verified the result by field sampling data. The spatial and temporal distribution of drought intensity was consistent with actual situation. Li, C. Q. and Li, H. J. [22] showed that Mar. to May's winter wheat TVDI in 2005 was highly consistent with $10 \mathrm{~cm}$ soil relative humidity, next is $20 \mathrm{~cm}$, the last is $50 \mathrm{~cm}$. Chen, C. et al. [23] used TVDI to monitor Xiaohuajian Basin drought, where there is complex topography, and the results can reflect the local drought situation. Therefore, in this study, TVDI was choosen for integrated winter wheat drought risk assessment.

\section{Background of Study Area}

Xingtai administrative district of Hebei Province locates in the middle part of North China, south east of the Taihang Mountains, between $113^{\circ} 52^{\prime}$ E- $115^{\circ} 49^{\prime}$ E, $36^{\circ} 50^{\prime} \mathrm{N}-37^{\circ} 47^{\prime} \mathrm{N}$. It has $12,439 \mathrm{~km}^{2}$ area and 7.26 million people. The topography is complex. From the west to east, there are mountains, hills and plains and their ratio is about 2:1:7. It belongs to temperate monsoon climate zone. The annual average temperature is $12{ }^{\circ} \mathrm{C}-13{ }^{\circ} \mathrm{C}$. The yearly precipitation is about $485 \mathrm{~mm}$, of which nearly $70 \%$ about falls in summer season from June to August. Xingtai belongs to Haihe River Basin. All of its rivers became seasonal river since the reservoirs began to operate in the end of 1960s.

Crops like winter wheat, rice, summer corn, spring corn, cotton, soybean, millet, potato etc., all can grow well. Historically, the farming system here was rotation and fallow, which had one harvest a year or three harvests within two years. Crop system altered into winter wheat-summer corn high water consumption crop structure with irrigation facility improvement since 1960s. The whole growing period of winter wheat is from October of the last year to June, which is the dry period. The natural precipitation can meet just about one third of winter wheat needed by high yield production. The main natural hazards include drought, flood, hail and strong wind, frost, plant diseases and insect pests etc.. The corresponding average yearly hazard impacted rate are $39.56 \%, 8.61 \%, 19.63 \%, 0.48 \%, 22.86 \%$ and $6.37 \%$ respectively. The crop failure ratio is $38.59 \%$, $10.34 \%, 23.75 \%, 0.43 \%, 20.59 \%$ and $6.29 \%$. Drought is the most severe hazard. Drought and drought 
coping become the biggest challenge for agriculture. Limited irrigation water badly restricts drought coping in mountains, hills and eastern low plain areas.

\section{Data and Method}

\subsection{Data Source}

The MODIS image data is from the website of NASA (National Aeronautics and Space Administration). They include 8 days' $1 \mathrm{~km}$ resolution synthetic surface temperature product MOD11A2 and 16 days' synthetic $250 \mathrm{~m}$ resolution vegetation index products MOD13Q1. The 16 days' MOD13Q1 data in normal precipitation year of 2006 were used and the winter wheat key growing period from March to May were divided into three key stages that is corresponding to turning green to jointing, jointing-heading, heading-filling period. Each stage is further divided into early and late stages. They are Feb. 27 to Mar. 6 and Mar. 7 to Mar. 22, Mar. 23 to Apr. 7 and Apr. 8 to Apr. 23, Apr. 24 to May 9 and May 10 to May 26. These stages are winter wheat's sensitive stages of water demand. The satisfaction of water will affect the growth of winter wheat, and ultimately affect the yield.

The images were processed as following steps. First, 8 days' MOD11A2 product was synthesized into 16 days' surface temperature product by software ENVI (The Environment for Visualizing Images). There were two circumstances. When both of the two 8 days' MOD11A2 are available, the average is taken. If only one 8 days' MOD11A2 is available, its value is directly as the synthesized value. Utilizing ArcGIS software, the first step is to stitch the synthesized and projected images of LST-Day (Land Surface Temperature-Day) wave band. Second, is to cut the images to get Xingtai's LST data with Geographic Lat/Lon projection and WGS-84 (World Geodetic System-1984 Coordinate System) datum plane. Third, is to resample the MOD13Q1 data and get the $1 \mathrm{~km}$ resolution data. Fourth, is to splice, projecte and cut the NDVI wave band with the same parameters as
MOD11A2 data processing. At last, the NDVI product that needed by TVDI calculation was gotten.

\subsection{TVDI Method}

There exists a negative correlation relationship between NDVI and LST. Price, J. C. [24] and Carlson, T. [25] found that NDVI and the scatterplot of inversed Ts presents triangular relationship. Sandholt, I. et al. [26] set up the TVDI model based on NDVI and LST correlation analysis.

$$
\begin{gathered}
\text { TVDI }=\left(T s-T s_{\text {min }}\right) /\left(T s_{\text {max }}-T s_{\text {min }}\right) \\
T s_{\text {min }}=a_{1}+b_{1} \times N D \\
T s_{\text {max }}=a_{2}+b_{2} \times N D
\end{gathered}
$$

In Eqs. (1), (2) and (3), $T_{s}$ is land surface temperature in any site; $T s_{\max }$ and $T s_{\min }$ are the highest and lowest land surface temperature corresponding to a same NDVI value in a certain period in the studying area; $a_{1}, a_{2}$ are undetermined coefficient; $b_{1}$ and $b_{2}$ are regression coefficient between land surface temperature and NDVI. TVDI value is between 0 and 1. Bigger TVDI means the severe drought. When TVDI is 0 , it means no drought occurs.

Utilizing the above models and ENVI software, the TVDI in each period was calculated based on LST and NDVI. The drought level was divided into five grades according to TVDI, namely moist $(0-0.2)$, normal (0.2-0.4), light drought (0.4-0.6), moderate drought (0.6-0.8) and heavy drought (0.8-1).

\subsubsection{LST of Xingtai during Mar. to May}

Matched with vegetation index, the processed LST images are shown as Fig. 1. At early March when winter wheat just began turning green, LST in western mountainous area was relatively low and most part in middle and east parts was relatively high. But at later stages, the relatively low LST was mainly in the middle part where distributes the most fertile land with relatively rich available water and has convenient irrigation facilities. 


\subsubsection{NDVI of Xingtai during Mar. to May}

Fig. 1 shows LST and NDVI of Xingtai from Mar. to May in 2006 is shown in Fig. 2. Generally, during the key growing period, the high NDVI was in central plain area, and the low in the mountainous and hilly areas as well as the low plains area. Late May, forest and shrub grass grow fast which increased the NDVI in the mountainous and hilly areas. The overall situation of NDVI is consistent with the actual growth of Winter Wheat (Fig. 2).

\subsubsection{TVDI of Xingtai}

With NDVI and LST data, TVDI was calculated. Drought intensity was classified and mapped heading to milking.

At the initial of turning green stage (a), the air temperature rose quickly, and spring irrigation had not started. Drought existed in most part of middle and eastern low plain area. The difference of drought severity was related to soil moisture before winter. At the followed stage of turning green to jointing (b), the air temperature continued to rise, which increased evaporation, and rainfall shortage exaggerated drought intensity. Severe and moderate drought expanded to almost the whole region including central plain that is the piedmont plain of Taihang (Fig. 3). The result shows that drought had been always existed during the whole growing stage of winter wheat from turning green, jointing, heading to milking. Only sporadic areas in the western edge of Taihang mountain where covers forest or middle and east plain areas show a wet state. At the middle stage of jointing (c), rainfall continued to remain low. Moderate and low drought existed in most part of Xingtai. At early heading stage (d), rainfall continued to remain low. Winter wheat is very sensitive to water in this period. Irrigation is the fundamental measure to guarantee the output. The areas with high irrigation capacity in the middle plain areas and the most eastern area were in a normal state. Other areas with insufficient irrigation capacity presented mild to severe drought. At late heading stage (e), drought intensity was eased by irrigation at

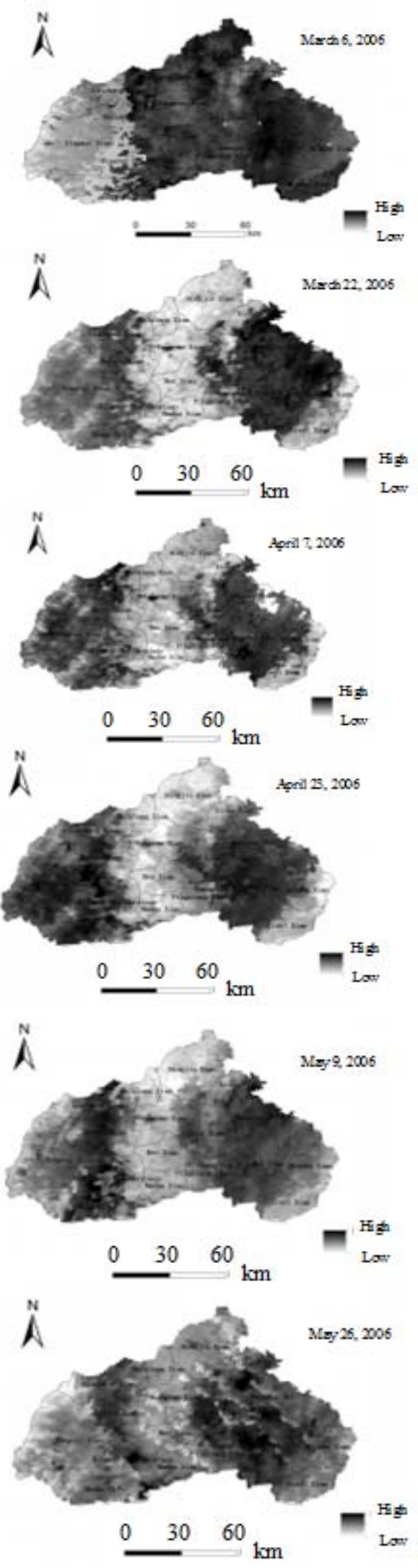

Fig. 1 LST. 

Administrative District in North China
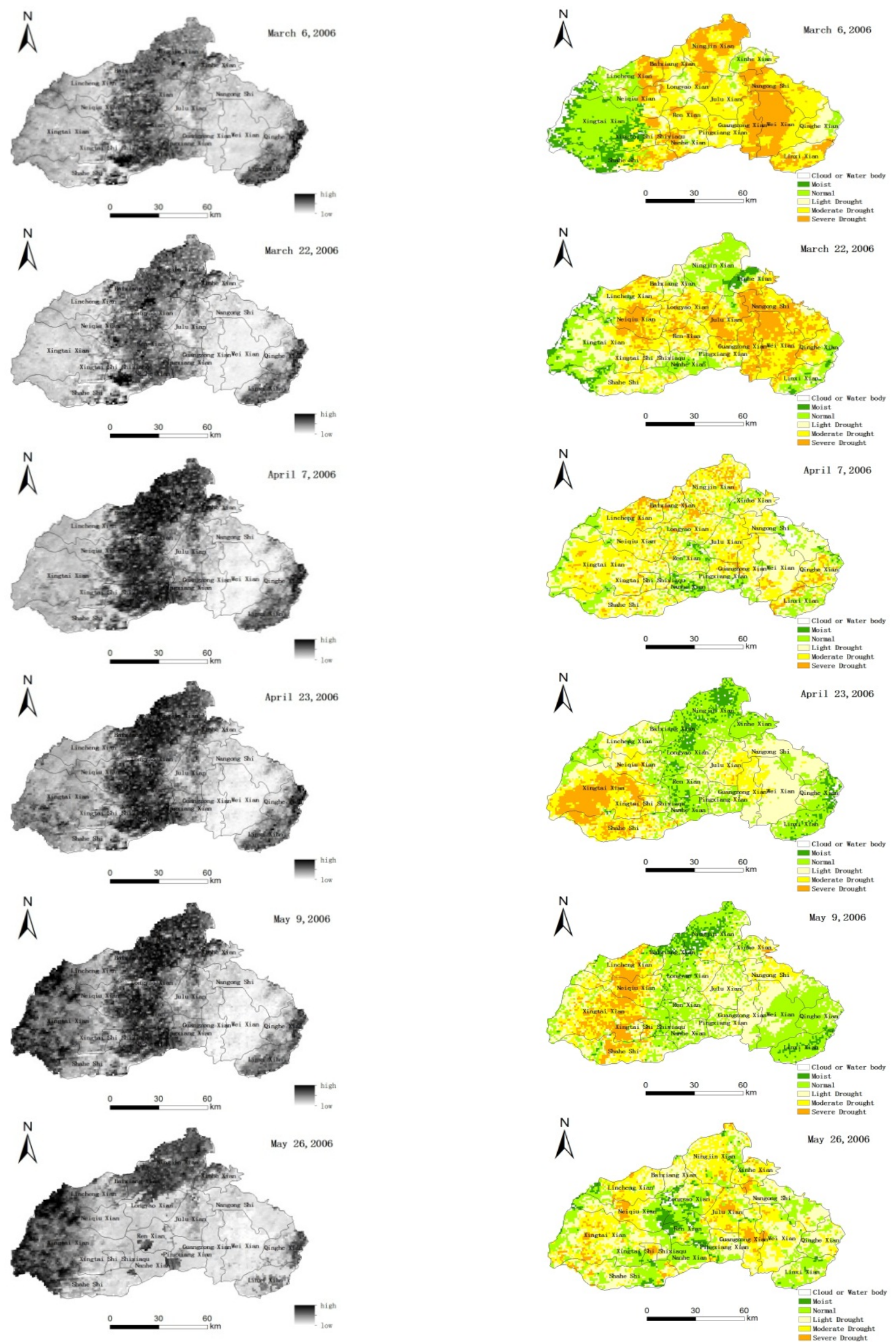

Fig. 2 NDVI of winter wheat during the key growing period in Xingtai district in 2006.

Fig. 3 Winter wheat TVDI in Xingtai from the reviving to filling stage, 2006. 
middle and eastern plain areas. But drought in western hilly and mountainous areas was intensified. At the filling stage of winter wheat (f), winter wheat is highly sensitive to water and the contribution of drought to reduction of yield was the largest. Western mountain and hilly areas and eastern low plain areas that had low irrigation capacity and water scarcity showed moderate to severe drought.

At the late stage of filling (e), rainfall increased slightly but still could not meet the needs of winter wheat water. The middle piedmont plain area was in a normal state and crop grew well. Drought in the western mountainous and hilly area and eastern low plain regions had been strengthened again.

\subsection{Comprehensive Drought Risk Assessment Model of} Winter Wheat

\subsubsection{Model}

The drought intensity of winter wheat during its key growing periods is determined by water deficiency rate, which is affected by multiple factors including precipitation, evaporation and transpiration, soil properties and soil moisture, irrigation, agronomic measures and so on. Comprehensive assessment of drought risk can reflect the spatial difference and provide scientific basis for agricultural drought disaster prevention and mitigation of different zones.

Based on winter wheat's each growth stage, TVDI was obtained by MODIS images and utilizing the weighted average method to construct the CDRA (Comprehensive Drought Risk Assessment) index. The weight is determined according to the impact of different drought intensity in each key period to yield. It is as:

$$
\mathrm{R}=\sum_{i=1}^{n} W_{i j} \times P_{i j}
$$

In Eq. (4), $R$ is the CDRA of winter wheat.

$\mathrm{p}_{i j}$ is winter wheat's $i$ growth stage and $\mathrm{j}$ class drought intensity TVDI; $W_{i j}$ is the weight of $i$ growth stage and $j$ class drought intensity TVDI. The higher the $\mathrm{R}$ value is, the greater yield reduction will be.

\subsubsection{Drought Risk Assessment and Mapping}

Based on Model 4 and using the above TVDI data, the CDRA of winter wheat in Xingtai administrative district of Hebei Province was carried out. By Kriging interpolation method, the comprehensive drought risk zoning of the study area in 2006 was finally obtained on the ArcGIS platform (Fig. 4). It presents that winter wheat drought risk is slight in the middle part, where is the fertile piedmont plain and with relatively complete irrigation system and available water. Extreme drought risk exists in the south-western mountainous and hilly area. Severe drought occurs in most part of eastern low plain area and north-western mountain and hilly area. Moderate drought risk exists in the transitional zone between slight drought risk and severe drought risk.

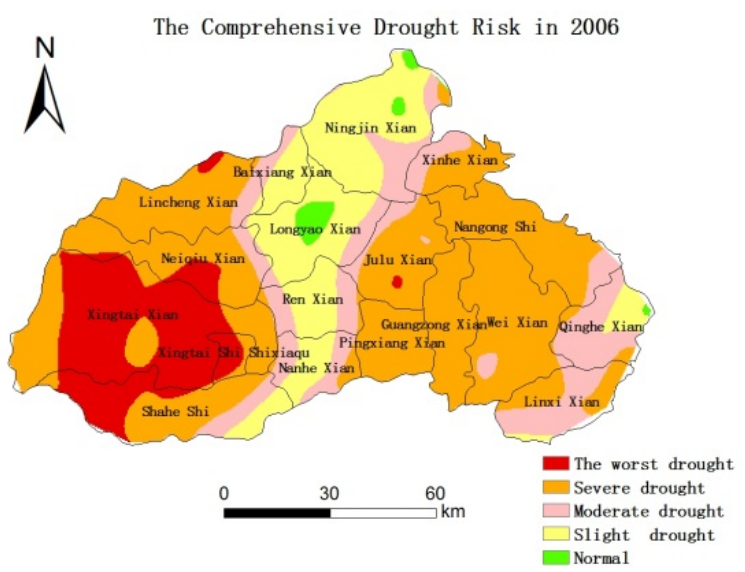

Fig. 4 The comprehensive drought risk of winter wheat during Mar. 3 to May, 2006.

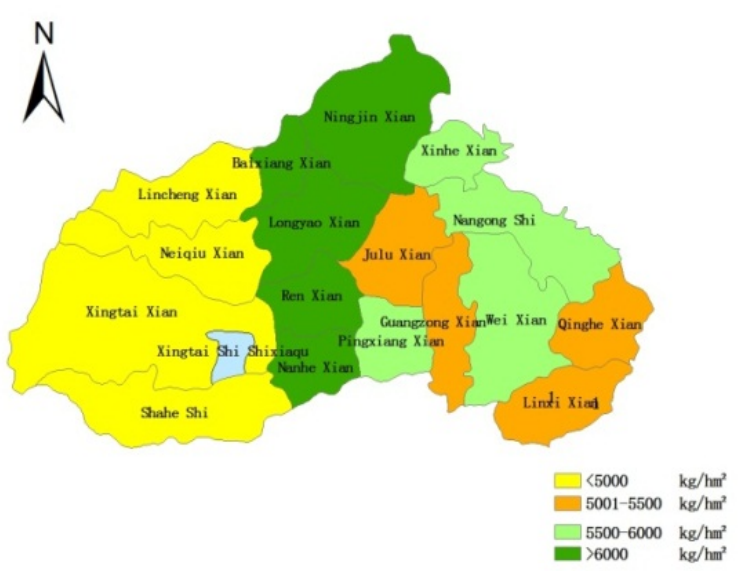

Fig. 5 Each counties' per unit area yield of winter wheat in 2006. 


\subsubsection{Verification of Winter Wheat Drought Risk} Assessment Result

To verify the risk assessment result, authors made a statistical analysis of the actual per unit yield of each county in 2006 and divided the yield into five levels, and then draw the yield distribution map (Fig. 5). Compared with the risk assessment result, it is found that there is remarkable negative relevant relations between winter wheat yield and drought risk level. The highest drought level corresponds to the lowest yield. And the lower level of drought corresponds to the higher yield. The temporal and spatial distribution is in keep with the practical situation in Xingtai.

\section{Conclusion and Discussion}

The study demonstrates that TVDI can be used in winter wheat drought monitor and risk assessment. In the same drought intensity trigged by rainfall shortage, crop failure risk in the piedmont plain area is the lowest, where soil is fertile and irrigation can be guarantied. While in mountainous and hilly region and the eastern plain area, drought risk of winter wheat is much higher due to water resources scarcity or continues overdraw of groundwater in last decades. The winter wheat-summer corn high water consumption crop structure needs to be adjusted urgently. According to water resources restriction, winter wheat sowing area in high risk areas should be reduced. Instead, some drought tolerant crops should be encouraged.

The result can be used by drought coping management. Also, further analysis of the root vulnerability cause based on the result can be used for long-term adaptive strategy determination.

\section{Acknowledgements}

The study was supported by the National Natural Science Foundation of China [No.46171501].

\section{References}

[1] Wang, Y. J., Shang, Y. R., and Guo, J. P. 2006. "Review of Monitor of Agricultural Drought Remote by Sensing
Method." Disaster 21 (4): 84-8.

[2] Commander of the National Flood Control and Drought Relief Office, the Ministry of Water Resources of Nanjing Institute of Hydrology and Water Resources. 1997. Floods and Drought in China. Beijing: China Water Conservancy and Hydropower Press: 281-357.

[3] Li, K. R., Xu, S. Y., and Guo, Q. Y. 1990. Drought and Flood Climate in North China Plain. Beijing: Science Press: 21-5.

[4] Palmer, W. C. 1965. Meteorological Drought. Tech. Report no. 45. U.S. Department of Commerce Weather Bureau Research. Washington, DC..

[5] McKee, T. B., Doesken, N. J., and Kleist, J. 1993. "The Relationship of Drought Frequency and Duration of Time Scales." In Proceedings of the Eighth Conference on Applied Climatology 17 (22): 179-83. Boston, MA: American Meteorological Society.

[6] Shafer, B. A., and Dezman, L. E. 1982. "Development of a Surface Water Supply Index (SWSI) to Assess the Severity of Drought Conditions in Snowpack Runoff Areas." Proceedings of the Western Snow Conference 50: 164-75.

[7] Palmer, W. C. 1968. "Keeping Track of Crop Moisture Conditions, Nationwide: The New Crop Moisture Index." Weatherwise 21: 156-61.

[8] Byun, H. R., and Wilhite, D. A. 1999. "Objective Quantification of Drought Severity and Duration." $J$. Clim. 12: 2747-56.

[9] Keyantash, J., and Dracup, J. A. 2002. "The Quantification of Drought: An Evaluation of Drought Indices." Bull. Am. Meteorol. Soc. 83 (8): 1167-80.

[10] Vicente-Serrano, S. M., Beguería, S., and López-Moreno, J. I. 2010. "A Multiscalar Drought Index Sensitive to Global Warming: The Standardized Precipitation Evapotranspiration Index.” J. Clim. 23: 1696-718.

[11] Mishra, A. K., and Singh, V. P. 2010. "A Review of Drought Concepts.” J. Hydrol. 391 (1): 202-16.

[12] Mishra, A. K., and Singh, V. P. 2011. "Drought Modeling-A Review.” J. Hydrol. 403 (1-2): 157-75.

[13] He, Y. 2013. "Assessment Research of Bijie Drought Risk Based on Cloud Model." Journal of Risk Analysis and Crisis Response 3 (4): 192-200.

[14] Li, R. F., Cheng, L., Ding, Y., Khorasani, K., Chen, Y., and Wang, W. 2013. "An Operational Drought Risk Management Framework Based on Stream-flow Intelligent Internet Control.” Journal of Risk Analysis and Crisis Response 3 (1): 34-43.

[15] Price, J. C. 1985. "On the Analysis of Thermal Infrared Imagery. The Limited Utility of Apparent Thermal Inertia." Remote Sensing of Environment 18 (1): 59- 73.

[16] Price, J. C. 1980. "The Potential of Remote Sensed Thermal Infrared Data to Infer Surface Soil Moisture and 


\section{Administrative District in North China}

Evaporation." Water Resources Research 16 (4): 787-95.

[17] Li, J. 2001. "Methods and Advances of Drought Monitoring by Remote Sensing." Hydrology 21 (4): 15-7.

[18] Jackson, R. D., Reginato, R. J., Pinter, P. J., and Idso, S. B. 1981. "Canopy Temperature as a Crop Water Stress Indicator." Water Resource Research 17 (4): 1133-8.

[19] Idso, S. B., Reginato, R. J., Pinter, P. J., Hatfield, J. L., and Jackson, R. D. 1981. "Normalizing the Stress-Degree-Day Parameter for Environmental Variability.” Agricultural Meteorology 24: 45-55.

[20] Qi, S. H., Wang, C. Y., and Niu, Z. 2003. "Evaluating Soil Moisture Status in China Using the Temperature/Vegetation Dryness Index (TVDI).” Journal of Remote Sensing 7 (5): 420-8.

[21] Wang, C. Z., Mao, L. X., He, Y., Han, L., Chen, J., and Yu, Z. 2009. "Application of Temperature-Vegetation Dryness Index (TVDI) in Estimation of Soil Moisture in the HHH Plain." Chinese Journal of Soil Science 40 (5): 998-1005.
[22] Li, C. Q., and Li, H. J. 2008. "The Application of TVDI in Drought Monitoring for Winter Wheat in Spring." Remote Sensing Technology and Application 23 (2): 161-5.

[23] Youjng, Z., Chen, C., Pingyong, B., JunZhan, W., and Chuan, H. 2009. "Drought Monitoring Model in the XiaohuajianValley.” Arid Land Geography 32 (6): 880-5.

[24] Price, J. C. 1990. "Using Spatial Context in Satellite Data to Infer Regional Scale Evapotranspiration." IEEE Transactions on Geosciences and Remote Sensing 28 (5): 940-8.

[25] Carlson, T. 2007. "An Overview of the "Triangle Method" for Estimating Surface Evapotranspiration and Soil Moisture from Satellite Imagery." Sensors 7 (8): 1612-29.

[26] Sandholt, I., Rasmussen, K., and Andersen, J. 2002. “A Simple Interpretation of the Surface Temperature/Vegetation Index Space for Assessment of Surface Moisture Status." Remote Sensing of Environment 79 (2): 213-24. 